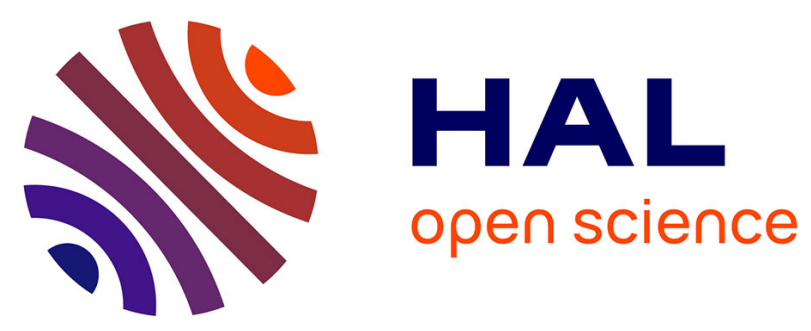

\title{
Frequent attendance in family practice and common mental disorders in an open access health care system.
}

Joanna Norton, Michel David, Guilhem de Roquefeuil, Jean-Philippe

Boulenger, Josip Car, Karen Ritchie, Anthony Mann

\section{- To cite this version:}

Joanna Norton, Michel David, Guilhem de Roquefeuil, Jean-Philippe Boulenger, Josip Car, et al.. Frequent attendance in family practice and common mental disorders in an open access health care system.. Journal of Psychosomatic Research, 2012, 72 (6), pp.413-8. 10.1016/j.jpsychores.2012.02.010 . inserm-00716022

\section{HAL Id: inserm-00716022 https://www.hal.inserm.fr/inserm-00716022}

Submitted on 9 Jul 2012

HAL is a multi-disciplinary open access archive for the deposit and dissemination of scientific research documents, whether they are published or not. The documents may come from teaching and research institutions in France or abroad, or from public or private research centers.
L'archive ouverte pluridisciplinaire HAL, est destinée au dépôt et à la diffusion de documents scientifiques de niveau recherche, publiés ou non, émanant des établissements d'enseignement et de recherche français ou étrangers, des laboratoires publics ou privés. 
Frequent attendance in family practice and common mental disorders in an open access health care system.

Joanna Norton, $\mathrm{PhD}^{\mathrm{a}, \mathrm{b}_{*}}$, Michel David, $\mathrm{MD}^{\mathrm{c}}$, Guilhem de Roquefeuil, MSc ${ }^{\mathrm{a}, \mathrm{b}}$, Jean-Philippe

Boulenger, MD, PhD ${ }^{\mathrm{d}}$, Josip Car, MD, $\mathrm{PHD}^{\mathrm{e}}$, Karen Ritchie, $\mathrm{PhD}^{\mathrm{a}, \mathrm{e}}$, Anthony Mann, MD, FRC Psych ${ }^{\mathrm{a}, \mathrm{f}}$

${ }^{\text {a } I N S E R M, ~ U 1061, ~ M o n t p e l l i e r, ~ F r a n c e ~}$

${ }^{\mathrm{b}}$ University Montpellier 1, Montpellier, France

${ }^{\mathrm{c}}$ Department of General Practice, University Montpellier 1, France

${ }^{\mathrm{d}}$ Department of Adult Psychiatry, La Colombière Hospital, University Montpellier 1, France

${ }^{\mathrm{e}}$ Imperial College, London, United Kingdom

${ }^{\mathrm{f}}$ Institute of Psychiatry, King’s College London, United Kingdom

*corresponding author

INSERM, U1061, Pathologies of the Nervous System, La Colombière Hospital, 39 avenue Charles Flahault, BP 34493, 34093 Montpellier Cedex 5, France

Tel: (0033)499614570

Fax: (0033)499614579

Email: joanna.norton@inserm.fr

Support: this work was supported by a grant from the French Ministry of Research as well as an unconditional grant from Lilly Pharmaceuticals.

Word Count : 257

Figures: 1, Tables: 2 


\begin{abstract}
Frequent attenders in family practice are known to have higher rates of mental disorder. However little is known about specific psychiatric disorders and whether this behavior extends to specialist services, in an open access fee-for-service health care system.
\end{abstract}

Methods: 1060 patients from 46 family practices completed the Patient Health Questionnaire and the Client Service Receipt Inventory. During the consultation, family practitioners blind to the questionnaire responses rated the severity of mental health and physical disorders. The $10 \%$ of patients with the highest number of six-month consultations in six age and sex stratified groups were defined as frequent attenders.

Results: After adjustment for sociodemographic variables, physical health and other psychiatric diagnoses, patients with a somatoform disorder were more likely to be frequent attenders, with a multi-adjusted odds ratio of 2.3 (95\% CI: 1.3-3.8, $\mathrm{p}=0.002)$.

Conclusion: when adjusting for confounders, among the four psychiatric diagnoses investigated only somatoform disorders remain significantly associated with frequent attendance. Physical health and chronic disease were no longer associated with FA which does not support the hypothesis that in an open access fee-for-service system, patients will consult for a wider range of health problems. Greater investigation into unexplained somatic symptoms could help reduce the frequency of attendance in both primary and secondary care, as FA appears to be a general health-seeking drive than extends beyond family practice.

Key words: frequent attenders, family practice, psychiatric disorders, health service utilization 


\section{Introduction}

Frequent attendance (FA) in primary care is of particular concern as it may reflect unmet patient needs [1], can lead to 'heartsink' in health care providers and places a significant burden on health resources $[2,3]$. The threshold for FA (number of visits or percentage with highest attendance rates) and the time range varies considerably between studies [2,4-7], leading to wide variations in rates, ranging from $2.7 \%$ of patients in a UK family practice [2] to $59.6 \%$ in Italy [8]. FA is higher in women $[2,3,9]$ and in higher age groups $[2,3]$, leading to a consensus definition of FA as the $10 \%$ age- and sex-stratified most frequent attenders (FAs) $[4,7,10]$.

FAs tend to have more socio-economic problems such as lack of social support, social isolation, and unemployment [7]. They show more family dysfunction [11], and are more likely to be divorced or widowed [7,9]. They are clinically heterogeneous exhibiting higher rates of non disease-specific physical and chronic illness [7,11-13]. Higher rates of FA are found in association with mental illness [11,14-19], the likelihood of FA increasing with anxiety disorder by a factor of 1.14 in a multi-adjusted model [19]. FAs also have higher rates of depressive symptoms [15,16,20,21], as well as somatoform symptoms or disorders [20-23]. Comorbid somatic and psychiatric symptoms would be more frequent in FAs [24]. It is likely that the profile of FAs will vary from one health care system to another depending on the burden FA behavior places on resources. According to Anderson and Newman's model, access and use of health care services is a function of enabling factors such as the ease of access to and availability of other types of care, predisposing factors such as sociodemographic characteristics and beliefs and finally need, both perceived and evaluated [1]. FA has been studied mainly in gatekeeping primary care systems where FAs present a substantial burden on the clinical workload which may lead patients to withhold from visiting their FP $[3,19]$. There is a gap in the literature concerning fee-for-service health care systems. 
Patients in such systems will have the choice of GP and between primary and secondary care, and will thereby self-select themselves for FP care rather than consulting the FP as a gateway to specialized services. It is thought that the FPs' attitude will make them less likely to withhold from consulting which will influence the type and diversity of symptoms for which they will consult.

In France, FPs are paid on a fee-for-service basis, directly by the patient. They work mainly alone with no ancillary staff. Up until 2005 they had no patient lists or gate-keeping role and patients were able to directly consult any FP or specialist as often as wanted with the same level of reimbursement by the state [25]. There were no checks or incentives from the national health system for FPs to reduce the frequency of attendance. This setting has allowed us to examine the association between frequent attendance behavior and specific common mental disorders in an open fee-for-service system, and to study whether FA is specific to family practice or whether it extends to other areas of health care which has seldom been explored before [12]. The main hypothesis is that FAs in the fee for service system will be consulting for a wider range of health conditions with a lesser prominence of mental illness than in more structured health care organizations.

\section{Methods}

The study was carried between October 2003 and April 2004, in a sample of FPs practicing in two urban and one semi-rural psychiatric catchment area, in and around the city of Montpellier. The urban study area covers a population of 140.000 inhabitants with 249 FPs and the semi-rural area a population of 80.000 with 73 FPs. In order to be representative of French family practice, the sample included both randomly selected FPs with a 'classic' practice-style and some FPs delivering alternative therapies (mainly acupuncture and homeopathy) who represent approximately $8 \%$ of French FPs [26]. FPs practicing in the study 
area were allocated a random number, listed accordingly, and contacted by telephone. The acceptance rate among the randomly selected FPs was $32.8 \%$. Because of the specificities of their practice (limited or no waiting area, or waiting time, few spaced-out consultations, many patients not in inclusion criteria), we drew a parallel list of GPs with an alternative practice style, who were contacted separately and selected for convenience purposes. In all, 46 FPs participated, 41 (27 urban, 14 semi-rural) with a classic' practice-style and 5 (4 urban, 1 semirural) with an alternative practice-style [27,28].

For each FP, a research assistant invited all eligible consecutive patients entering the waiting room to complete self-administered questionnaires until 25 patients per FP had participated. Exclusion criteria were being younger than 18 years, not living in the study area and not consulting for one's self. The patient response rate was $89.8 \%$.

\section{Instruments}

During the consultation, FPs completed a short questionnaire with, for physical illness and psychiatric symptoms, an estimation of severity on a 5-point scale with a clear indication that ratings of three and above (mild, moderate or severe) were considered as cases of physical or psychiatric disorder, respectively. For cases, FPs were asked to write down their diagnoses; somatic diagnoses were later classified into chronic disease or not by a FP researcher, based on ICD-10 classification criteria [29].

Patients completed the following self-administered questionnaires: a brief socio-demographic and health questionnaire, the Patient Health Questionnaire (PHQ) [30], the Brief Disability Questionnaire (BDQ) [31], an adapted version of the Client Service Receipt Inventory [32], with an open question on the reason for the visit. By applying DSM-IV-based diagnostic algorithms, the PHQ provides provisional diagnoses of anxiety, mood and somatoform disorders, meeting DSM IV criteria (major depression, panic disorder, other anxiety 
disorders), or subthreshold (other depressive disorders, somatoform disorders) [30]. For somatoform disorders, patients meeting caseness criteria which had been rated by the FP as moderately or severely physically ill were re-classified as non-cases. This was the only proxy available for ruling out 'an adequate biological explanation' for the symptoms as required for the diagnosis.

The PHQ was translated into French following rigorous translation guidelines (translation/back-translation). It has not yet been validated in French family practice. For the CSRI, a rigorous translation was not considered necessary as it had to be adapted to fit the organization of the French health care system.

\section{Study variables}

Dependent variable: FA was defined as the top $10 \%$ of survey-day patients with the highest number of self-reported visits to a family practice surgery (survey-day visit included) over the past six months in each of six sex and age stratified groups $[7,10]$.

Independent variables:

Following Anderson and Newman's framework [1] patient variables were grouped into: predisposing factors, perceived need and evaluated need (see Table 1). Predisposing factors included socio-demographic variables. Perceived need included patient-declared physical health problem, treatment for physical health problem, being bothered by personal or social problems and the reason for the visit. Evaluated need was assessed using both patient information and FP evaluation: patient-rated disability, patient report of anxiolytic or antidepressant treatment, PHQ psychiatric diagnoses, and FP-rated presenting symptoms (classified as psychological yes/no), physical and mental health.

Service utilization: Over this period, patients also indicated whether they had always visited the same FP or not. Doctor-shoppers (defined as visiting two or more different FPs) indicated 
how many different FPs they had visited and the reason for seeing a different FP (practical or because of dissatisfaction with some aspect of previous care).

Analysis

The analysis was carried out on 1060 patients with complete data for the main study variables and 1044 patients for the final model, which represents $91 \%$ of the total sample $(n=1151)$. Percentages are given for categorical variables and medians (range) for skewed continuous or score variables. For the descriptive analysis, we used Wilcoxon two-sample T-test and Kruskal-Wallis test for testing differences between skewed distributions.

In order to take into account the two-stage sampling process, marginal generalized estimating equations were used to test associations (GENMOD SAS procedure, option repeated) in the univariate and multivariate analyses. Variables associated with FA in the univariate analysis with p-values $<0.10$ were considered for entry as adjustment variables in the multivariate model. Odds ratios (OR) with their $95 \%$ confidence intervals $(\mathrm{CI})$ are given. Statistical analyses were performed using SAS version 9.1 (SAS Institute, Cary, NC, USA).

\section{Results}

Description of the FP and patient sample

Median FP age was 45 years (range: $32-59$ ) and similar for both sexes. Of the FPs, 56\% were male; $60 \%$ had been practicing 10 years or more and $80 \%$ declared having trained in mental health in the past 3 years. Two-thirds practiced alone.

Of the 1060 patients, $61.8 \%$ were female. Median age was 42 (range: 18-93); 49.4\% were married and 33.5\% single; $33.5 \%$ had a high (post-school) educational level. $40.1 \%$ were working, $10.6 \%$ unemployed, $14.3 \%$ students and $35 \%$ retired. Overall, $11.3 \%$ for a 
somatoform disorder, $7.5 \%$ for subthreshold depression, $8.7 \%$ major depression, $16.1 \%$ panic disorder and $7.7 \%$ other anxiety disorder.

The median number of visits to a FP during the past 6 months (survey-day visit included) was 3 (range: 1-65). Women made significantly more visits than men (Wilcoxon two-sample Ttest: $\mathrm{p}=0.037)$ and the number of visits increased with age (Kruskal-Wallis test: $\mathrm{p}=0.004)$. The distribution of FAs among the 46 study FPs is given in Figure 1.

-insert Figure 1 here-

To be classified as a FA (top $10 \%$ consultation frequency), the number of visits required by sex and age group was as follows: for men, 7 visits or more for the under 30s, 8 visits or more for the 30 to 49 year olds and 6 visits or more for the over 50s. For women, these figures are of 10,10 and 7 for the three age groups respectively.

\section{Factors associated with FA: univariate analysis}

FAs had significantly higher rates of chronic disease $(\mathrm{p}<0.042)$ and of patient-declared physical illness $(\mathrm{p}<0.0001)$ (Table 1). FP ratings of psychiatric disorder were twice as high among FAs $(\mathrm{p}<0.0001)$. The proportion of patients with a psychiatric disorder, whatever the diagnosis, was significantly higher among FAs.

Of the FAs, 40.9\% were doctor-shoppers. FAs always visiting the same FP were more often rural $(p=0.03)$, with a lower level of education $(p=0.016)$, less personal and social problems $(\mathrm{p}=0.04)$, higher levels of disability $(\mathrm{p}=0.009)$ and less visits to mental health professional $(\mathrm{p}=0.006)$ than doctor-shopping FAs. There were no significant differences regarding physical and mental health (results not shown).

-insert Table 1 here- 
FA behavior was not associated with medication prescription (all types), additional somatic exploration, referral to a specialist or support and advice. However, follow-up appointments were significantly more frequent among FAs (19\% versus $12.1 \%, \mathrm{p}=0.044)$ and survey-day prescription of psychotropic medication was higher ( $21 \%$ versus $13.1 \%, \mathrm{p}=0.0003)$.

Factors associated with FA: multivariate analysis

When entering all four psychiatric diagnostic categories simultaneously into a unadjusted model, the strongest association with FA was for somatoform disorders $(\mathrm{OR}=2.3$ (95\% CI: 1.46-3.60, $\mathrm{p}=0.0003)$, followed by anxiety disorders excluding panic $(\mathrm{OR}=2.02(95 \% \mathrm{CI}$ : 1.13-3.61, $\mathrm{p}=0.02$ ); depressive disorders and panic disorder becoming non-significant (not shown).

Table 2 shows the association between the psychiatric diagnostic categories, health care utilization variables and FA, further adjusted for confounders. With regard to psychiatric diagnoses, only somatoform disorders remained significantly associated with FA (OR=2.27 (95\% CI: $1.34-3.85, \mathrm{p}=0.002$ ). Among the health care utilization variables, only specialist consultations and doctor-shopping remained significantly associated with FA. Patients seeing 1, or 2 or more specialists were respectively 2.1 (95\% CI: $1.15-3.83)$ and 3.08 (95\% CI: 1.98 4.80) $(\mathrm{p}<0.0001)$ times more likely to be FAs, compared to those seeing no specialists over the past 6 months.

-insert Table 2 here-

\section{Discussion}

Association between psychiatric disorders and FA in family practice

Previous studies have shown in multi-adjusted analyses that psychiatric disorders have a significant influence on FA in family practice $[15,19]$. Our results are in keeping with the 
latter with patients with a a somatoform disorder being more than twice as likely as others to be FAs. However, our findings do not support the hypothesis that FAs will present for a wider range of health problems, chronic disease status and physical illness failing to reach significance in the final model.

With regard to the type of psychiatric disorder, only somatoform disorders remained significantly associated with FA behavior after adjusting for depression, panic and anxiety disorders as well as other confounders in the final model. Few studies have examined the association between FA behavior and a range of psychiatric disorders. Sheehan et al. (2003) found an association between somatization and FA in older primary care attenders, controlling for depression and physical illness, neither of which remained significant [20]. The lack of association with depression could be explained by the increased ability of FPs to detect this disorder $[31,33]$ and therefore treat patients in primary care or refer them for specialist care. However, Gili et al. (2011) found that after adjusting for other ICD-10 psychiatric disorders, somatoform as well as depressive disorders remained associated with frequent attendance [21]. Another explanation for our finding could be the direct access to mental health care professionals in the open access fee-for-service system. This however requires that patients recognize and acknowledge their symptoms, overcome the stigma sometimes attached to visiting a mental health professional and self-refer themselves for specialist care. This is more likely for anxiety and depressive symptoms than for somatoform symptoms which patients tend not view as being linked to a psychiatric condition. There is a tradition of psychotherapy in France which possibly makes it more culturally and socially acceptable for people to consult a mental health professional than elsewhere, which gives weight to this explanation.

With regard to somatoform disorder, FA over the 6-month recall period in our study may reflect time-to-diagnosis for more complex clinical pictures including unrecognized physical 
health problems or hidden psychiatric symptoms not yet picked up on by the FP, thus reflecting transient rather than persistent FA [5]. However, the association between somatoform disorders and FA is in keeping with a large body of evidence from elsewhere [2022]. In fact it has recently been suggested that a redrawing of the diagnostic criteria for the category somatoform disorders is needed, focusing on its main attributes: somatic symptoms, excess concern with symptoms and illness and abnormal health care utilization [34]. Contrary to results found elsewhere for chronic disease and medical problems $[7,12,13]$, FPrated physical health, personal and social problems, disability and chronic disease were not associated with FA when adjusting for confounders. This does not support the hypothesis that FAs would show a greater variety of health conditions in the fee-for-service system. This could be because patients in France at the time of the study were able to consult any FP at will. We previously found on data from the same study that patients with a common mental disorder (depression, anxiety, panic or somatoform disorder) who had doctor-shopped over the previous six months were more likely to have their psychiatric disorder detected on the survey day, but only if they had changed FP because of dissatisfaction with previously received care [28]. The lack of association between chronic disease status, physical health and FA would therefore reflect appropriate management of these conditions in general practice, with patients being able to choose the FP which suits them best. As FPs worked mainly alone with no ancillary staff, it could also reflect the role of independently working nurses making home-visits on prescription for the more severe cases of chronic disorder. FP home-visits were not included in the definition of FA which may also contribute to the lack of association.

\section{Association between FA in family practice and use of other health care services}

Few studies report on the association between FA in primary care and other areas of care $[12,17,23]$. Our findings indicate as elsewhere that FA behavior is not restricted to family 
practice as this behavior extends into secondary care and contact with both medical and paramedical services, suggesting unmet need at both the primary and secondary care level. The higher use of secondary care services could be the consequence of referral on the behalf of the FP. This however appears unlikely in our study given that FAs were no more likely to be referred to specialists than non-FAs. In the final model, only consulting a specialist physician remained significantly associated with FA. This fits with the finding that somatoform disorders only, which patients will not necessarily view as being related to a psychiatric condition, remain associated with FA.

Nearly half of FAs in the current study were doctor-shoppers, which in itself could account for their FA status, and a quarter doctor-shopped because of dissatisfaction with previous care. The profile of FAs differed somewhat according to whether they were doctor-shoppers or not, doctor-shopping FAs having more social and personal problems and seeking psychological help whilst non-doctor-shopping FAs being more often rural, with lower levels of education and higher levels of disability. Although the clinical heterogeneity of FAs is largely documented, this suggests the type of FA ("pure FAs", doctor-shopping FAs further broken down by reason for doctor-shopping) should also be considered when applicable in further studies.

\section{Strengths and limits}

The study limitations are described in detail elsewhere $[27,28]$. The main limitation is the low (33\%) but common FP participation rate [35] which may have led to the selection of FPs particularly interested in mental health issues. Self-reported service use was recorded over the past six months in order to minimize recall bias, as it was not possible to collect data from patient files (patients being able to visit any FP at the time of the study). Although the 6- 
month time frame may have overestimated FA by classifying as FA patients with acute health problems, this was considered the best compromise for obtaining self-report information. Concerning the definition of FAs, we followed the recommendations of Smits et al (2009) who compared different classification methods [5]. However, we were unable to take into account patients not consulting at all over the recall period, which will have reduced the threshold of the number of visits necessary for being considered a FA. The recruitment of consecutive patients rather than a random sample may also have overestimated the FA rate [36]. Caution is required in the interpretation of our findings as mental illness influencing service use requires that the patient had the condition at the beginning of the 6-month period. Yet we have no data on previous visits, on whether they were initiated by the patient or the FP, or on whether the FP had detected a psychiatric disorder. Finally, we were not able to rule out a biological explanation of illness as requested in DSM-IV for somatoform disorders. We used physical illness status as a proxy, which will no doubt have led to some misclassifications.

Despite these limits, the study included a large sample of FP attenders, with a high participation rate, assessed by internationally accepted measures. This is one of the first studies to examine the association between the main psychiatric disorders encountered in primary care and FA behavior in an open access fee-for-service system and thus fills a gap on the knowledge of FA behavior. The open access health care system in place at the time of the study meant we were able to examine FA behavior in both primary and secondary care.

\section{Conclusion}

These findings from a cross-sectional study of a large sample of French FP attenders show that even when patients have direct access to specialist services, FA in family practice remains strongly associated with common mental disorders. Among the specific diagnostic 
categories, somatoform disorders only predispose to higher rates of care-seeking, which might be reduced if unexplained somatic symptoms were better detected and managed. Along with improved care coordination, this could help reduce multiple visits to different health care providers. In France, the 2005 FP-registration scheme is likely to have changed the pattern of frequent attendance, with more centralized care and referral to secondary care, direct access being discouraged by lower reimbursement rates. With the exception of Bellon et al.'s trial which showed the success of a comprehensive FP intervention scheme with FAs to reduce this behavior [37], interventions to reduce the consultation patterns of FAs have so far shown limited results [38].

Acknowledgments:

Authorization to translate and use the PRIME-MD® Patient Health Questionnaire@ 1999, Pfizer Inc. was kindly given by Dr. Robert L Spitzer who can be contacted for research information at rls8@ columbia.edu. This work was supported by a grant from the French Ministry of Research as well as an unconditional grant from Lilly Pharmaceuticals. The 46 study FPs were given $150 €$ for their participation. We would like to thank all the patients and FPs who participated in the study, and the research assistants who helped collect code and enter the data.

Conflicts of interest: none 
References

1. Andersen R, Newman J. Societal and Individual Determinants of Medical Care Utilization in the United States. The Milbank Quarterly, 2005, 83:1-28.

2. Gill D, Dawes M, Sharpe M, Mayou R. GP frequent consulters: their prevalence, natural history, and contribution to rising workload. Br J Gen Pract, 1998, 48:1856-7.

3. Neal RD, Heywood PL, Morley S, et al. Frequency of patients' consulting in general practice and workload generated by frequent attenders: comparisons between practices. $\mathrm{Br} \mathrm{J}$ Gen Pract, 1998, 48:895-8.

4. Luciano JV, Fernandez A, Pinto-Meza A, et al. Frequent attendance in primary care: comparison and implications of different definitions. Br J Gen Pract, 2010, 60:49-55.

5. Smits FT, Brouwer HJ, ter Riet G, van Weert HC. Epidemiology of frequent attenders: a 3year historic cohort study comparing attendance, morbidity and prescriptions of one-year and persistent frequent attenders. BMC Public Health, 2009, 9:36.

6. Smits FT, Brouwer HJ, van Weert HC, et al. Predictability of persistent frequent attendance: a historic 3-year cohort study. Br J Gen Pract, 2009, 59:e44-50.

7. Vedsted P, Christensen MB. Frequent attenders in general practice care: a literature review with special reference to methodological considerations. Public Health, 2005, 119:118-37.

8. Menchetti M, Belvederi Murri M, Bertakis K, et al. Recognition and treatment of depression in primary care: effect of patients' presentation and frequency of consultation. $\mathbf{J}$ Psychosom Res, 2009, 66:335-41.

9. Scaife B, Gill P, Heywood P, Neal R. Socio-economic characteristics of adult frequent attenders in general practice: secondary analysis of data. Fam Pract, 2000, 17:298-304.

10. Smits FT, Mohrs JJ, Beem EE, et al. Defining frequent attendance in general practice. BMC Fam Pract, 2008, 9:21.

11. Bellon JA, Delgado A, Luna JD, Lardelli P. Psychosocial and health belief variables associated with frequent attendance in primary care. Psychol Med, 1999, 29:1347-57.

12. Kersnik J, Svab I, Vegnuti M. Frequent attenders in general practice: quality of life, patient satisfaction, use of medical services and GP characteristics. Scand J Prim Health Care, 2001, 19:174-7.

13. Little P, Somerville J, Williamson I, et al. Psychosocial, lifestyle, and health status variables in predicting high attendance among adults. Br J Gen Pract, 2001, 51:987-94.

14. Bebbington PE, Meltzer H, Brugha TS, et al. Unequal access and unmet need: neurotic disorders and the use of primary care services. Psychol Med, 2000, 30:1359-67. 
15. Dowrick CF, Bellon JA, Gomez MJ. GP frequent attendance in Liverpool and Granada: the impact of depressive symptoms. Br J Gen Pract, 2000, 50:361-5.

16. Menchetti M, Cevenini N, De Ronchi D, et al. Depression and frequent attendance in elderly primary care patients. Gen Hosp Psychiatry, 2006, 28:119-24.

17. Svab I, Zaletel-Kragelj L. Frequent attenders in general practice: a study from Slovenia. Scand J Prim Health Care, 1993, 11:38-43.

18. Vazquez-Barquero JL, Wilkinson G, Williams P, et al. Mental health and medical consultation in primary care settings. Psychol Med, 1990, 20:681-94.

19. Wyke S, Hunt K, Walker J, Wilson P. Frequent attendance, socioeconomic status and burden of ill health. An investigation in the west of Scotland. Eur J Gen Pract, 2003, 9:4855.

20. Sheehan B, Bass C, Briggs R, Jacoby R. Somatization among older primary care attenders. Psychol Med, 2003, 33:867-77.

21. Gili M, Luciano JV, Serrano MJ, et al. Mental disorders among frequent attenders in primary care: a comparison with routine attenders. J Nerv Ment Dis, 2011, 199:744-9.

22. Katon W, Von Korff M, Lin E, et al. Distressed high utilizers of medical care. DSM-III-R diagnoses and treatment needs. Gen Hosp Psychiatry, 1990, 12:355-62.

23. Reid S, Wessely S, Crayford T, Hotopf M. Frequent attenders with medically unexplained symptoms: service use and costs in secondary care. Br J Psychiatry, 2002, 180:248-53.

24. Ferrari S, Galeazzi GM, Mackinnon A, Rigatelli M. Frequent attenders in primary care: impact of medical, psychiatric and psychosomatic diagnoses. Psychother Psychosom, 2008, 77:306-14.

25. Bourgueil Y, Marek A, Mousques J. Trois modèles types d'organisation des soins primaires en Europe, au Canada, en Australie et en Nouvelle-Zélande. Quest Eco Santé, $2009,141$.

26. Darrine S, Niel X. Les médecins omnipraticiens au 1er janvier 2000. DREES: Direction de la Recherche, des Etudes, de l'Evaluation et des Statistiques - Etudes et Résultats, 2001, $\mathrm{N}^{\circ} 99$.

27. Norton J, De Roquefeuil G, Boulenger JP, et al. Use of the PRIME-MD Patient Health Questionnaire for estimating the prevalence of psychiatric disorders in French primary care: comparison with family practitioner estimates and relationship to psychotropic medication use. Gen Hosp Psychiatry, 2007, 29:285-93.

28. Norton J, de Roquefeuil G, David M, et al. The mental health of doctor-shoppers: Experience from a patient-led fee-for-service primary care setting. J Affect Disord, 2011.

29. WHO. The ICD-10 Classification of Mental and Behavioral Disorders - Diagnostic Criteria for Research. Geneva, World Health Organisation, 1993. 
30. Spitzer RL, Kroenke K, Williams JB. Validation and utility of a self-report version of PRIME-MD: the PHQ primary care study. Primary Care Evaluation of Mental Disorders. Patient Health Questionnaire. Jama, 1999, 282:1737-44.

31. Ustun TB, Sartorius N, editors. Mental Illness in General Health Care. An International Study. Chichester: John Wiley \& Sons; 1995.

32. Beecham J, Knapp M. Costing psychiatric interventions. In: Thornicroft G, Brewin C, Wing J. Measuring Mental Health Needs. London, Gaskell, 1992: 163-83.

33. Norton J, de Roquefeuil G, David M, et al. [Prevalence of psychiatric disorders in French general practice using the patient health questionnaire: comparison with GP caserecognition and psychotropic medication prescription]. Encephale, 2009, 35:560-9.

34. Puri PR, Dimsdale JE. Health care utilization and poor reassurance: potential predictors of somatoform disorders. Psychiatr Clin North Am, 2011, 34:525-44.

35. Deehan A, Templeton L, Taylor C, et al. The effect of cash and other financial inducements on the response rate of general practitioners in a national postal study. $\mathrm{Br} \mathbf{J}$ Gen Pract, 1997, 47:87-90.

36. Lee ML, Yano EM, Wang M, et al. What patient population does visit-based sampling in primary care settings represent? Med Care, 2002, 40:761-70.

37. Bellon JA, Rodriguez-Bayon A, de Dios Luna J, Torres-Gonzalez F. Successful GP intervention with frequent attenders in primary care: randomised controlled trial. Br J Gen Pract, 2008, 58:324-30.

38. Smits FT, Wittkampf KA, Schene AH, et al. Interventions on frequent attenders in primary care. A systematic literature review. Scand J Prim Health Care, 2008, 26:111-6. 


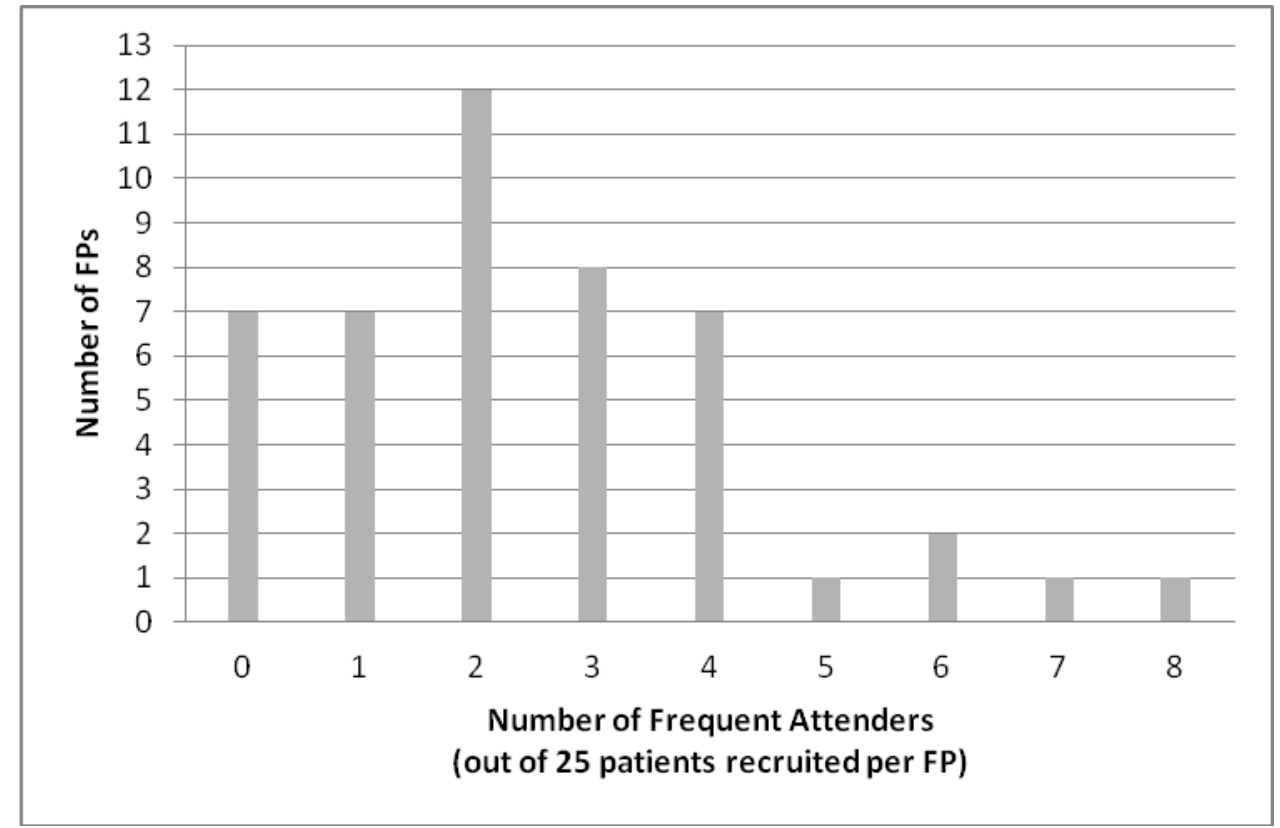

Figure 1. Distribution of FPs according to their number of frequent attenders. 
Table 1. Socio-demographic and health characteristics of Frequent Attenders (N=1060)

\begin{tabular}{|c|c|c|c|c|c|c|}
\hline & & Not & A (945) & & & \\
\hline Variables & & $\mathrm{n}$ & $\%$ & $\mathrm{n}$ & $\%$ & $\mathrm{p}$ \\
\hline Study area & Urban & 622 & 65.82 & 88 & 76.52 & 0.033 \\
\hline Predisposing factors: & & & & & & \\
\hline Marital status & Married & 78 & 50.58 & 46 & 40.00 & \\
\hline & Single & 316 & 33.44 & 39 & 33.91 & \\
\hline & $\mathrm{D} / \mathrm{S} / \mathrm{W}^{*}$ & 151 & 15.98 & 30 & 26.09 & 0.06 \\
\hline Education & Low & 252 & 26.67 & 42 & 36.52 & \\
\hline & Medium & 365 & 38.62 & 46 & 40.00 & \\
\hline & High & 328 & 34.71 & 27 & 23.48 & 0.004 \\
\hline Occupation & Employed & 394 & 41.69 & 32 & 27.83 & \\
\hline & Unemployed & 91 & 9.63 & 21 & 18.26 & \\
\hline & Student & 143 & 15.13 & 8 & 6.96 & \\
\hline & Retired & 317 & 33.54 & 54 & 46.96 & $<.0001$ \\
\hline Perceived need (patient-rated): & & & & & & \\
\hline Physical health problem & Yes & 439 & 46.46 & 76 & 66.09 & $<.0001$ \\
\hline TT for physical health problem & Yes & 316 & 33.44 & 68 & 59.13 & $<.0001$ \\
\hline Bothered social or personal problems & Not at all & 531 & 56.19 & 56 & 48.70 & \\
\hline & A little & 327 & 34.60 & 38 & 33.04 & \\
\hline & A lot & 87 & 9.21 & 21 & 18.26 & 0.04 \\
\hline Reason for visit: psychological & Yes & 58 & 6.14 & 17 & 14.78 & 0.002 \\
\hline Evaluated need & & & & & & \\
\hline Disability (BDQ) & None/Mild & 630 & 66.67 & 56 & 48.70 & \\
\hline & Moderate & 233 & 24.66 & 32 & 27.83 & \\
\hline & Severe & 82 & 8.68 & 27 & 23.48 & $<.0001$ \\
\hline Physical health (FP-rated) & Mild (non-case) & 372 & 39.37 & 38 & 33.04 & \\
\hline & Moderate & 348 & 36.83 & 42 & 36.52 & \\
\hline & Severe & 225 & 23.81 & 35 & 30.43 & 0.232 \\
\hline
\end{tabular}




\begin{tabular}{|c|c|c|c|c|c|c|}
\hline Chronic illness (FP-rated) & Yes & 268 & 28.36 & 43 & 37.39 & 0.042 \\
\hline Psychiatric disorder (FP-rated) & Yes & 236 & 24.97 & 61 & 53.04 & $<.0001$ \\
\hline Presenting symptoms: psychological (FP) & Yes & 214 & 22.65 & 49 & 42.98 & $<.0001$ \\
\hline Anxiol/antidepressant treatment (patient) & Yes & 129 & 13.65 & 36 & 31.30 & $<.0001$ \\
\hline \multicolumn{7}{|l|}{ Psychiatric disorders (PHQ): } \\
\hline Somatoform disorder & Yes & 89 & 9.42 & 29 & 25.22 & $<.0001$ \\
\hline \multirow[t]{3}{*}{ Depressive disorder } & No & 809 & 85.61 & 80 & 69.57 & \\
\hline & Minor & 67 & 7.09 & 12 & 10.43 & \\
\hline & Major & 69 & 7.30 & 23 & 20.00 & $<.0001$ \\
\hline Panic disorder & Yes & 61 & 6.46 & 21 & 18.26 & $<.0001$ \\
\hline Other anxiety disorder & Yes & 43 & 4.55 & 19 & 16.52 & $<.0001$ \\
\hline \multicolumn{7}{|l|}{ Service utilization: } \\
\hline \multirow[t]{3}{*}{ Doctor-shopping } & No & 697 & 73.76 & 68 & 59.13 & \\
\hline & Yes, practical & 172 & 18.20 & 23 & 20.00 & \\
\hline & Yes, dissatisfied & 76 & 8.04 & 24 & 20.87 & $<.0001$ \\
\hline \multirow[t]{3}{*}{ Consulted specialist physician } & 0 & 489 & 51.75 & 26 & 22.61 & \\
\hline & 1 & 178 & 18.84 & 22 & 19.13 & \\
\hline & $2+$ & 278 & 29.42 & 67 & 58.26 & $<.0001$ \\
\hline Consulted a mental health professional $* *$ & Yes & 80 & 8.61 & 30 & 26.09 & $<.0001$ \\
\hline Visited paramedical staff*** & Yes & 191 & 20.21 & 43 & 37.39 & $<.0001$ \\
\hline Visited social worker & Yes & 28 & 2.96 & 15 & 13.04 & $<.0001$ \\
\hline Survey-day FP is usual FP & Yes & 746 & 79.03 & 102 & 88.70 & 0.013 \\
\hline
\end{tabular}

*D/S/W: divorced, separated or widowed

**psychiatrist, psychologist or psychotherapist $(\mathrm{N}=1044)$

****physiotherapist, osteopath, nurse.. 
Table 2. Frequent attendance according to psychiatric diagnosis and service utilization: multivariate analysis $(\mathrm{N}=1044)$

\begin{tabular}{|c|c|c|c|c|c|c|}
\hline \multirow[b]{2}{*}{ Predisposing factors: } & \multicolumn{2}{|l|}{ Variable (reference category) } & \multirow{2}{*}{\begin{tabular}{|c|} 
OR \\
0.87 \\
\end{tabular}} & \multicolumn{2}{|c|}{$(95 \% \mathrm{CI})$} & \multirow{2}{*}{$\mathrm{p}$} \\
\hline & Education (low) & Medium & & $(0.54$ & 1.40) & \\
\hline & & High & 0.39 & $(0.24$ & $0.65)$ & 0.0002 \\
\hline \multirow[t]{8}{*}{ Evaluated need: } & PHQ psychiatric diagnoses: & & & & & \\
\hline & Somatoform disorder (no) & Yes & 2.27 & $(1.34$ & $3.85)$ & 0.002 \\
\hline & Depressive disorder (no) & Minor & 1.02 & $(0.55$ & $1.92)$ & \\
\hline & & Major & 0.89 & $(0.34$ & 2.33) & 0.96 \\
\hline & Panic disorder (no) & Yes & 1.25 & $(0.65$ & 2.40) & 0.42 \\
\hline & Other anxiety disorder (no) & Yes & 1.71 & $(0.77$ & $3.81)$ & 0.19 \\
\hline & Physical health problem (FP-rated) (no) & Yes & 1.00 & $(0.56$ & 1.77) & 0.99 \\
\hline & Chronic illness (FP-rated) (no) & Yes & 1.08 & $(0.63$ & 1.85) & 0.78 \\
\hline Perceived need: & Physical health problem (patient-rated) (no) & Yes & 1.33 & $(0.85$ & 2.08) & 0.21 \\
\hline \multirow[t]{7}{*}{ Service utilization: } & Doctor-shopping (no) & Yes, practical & 1.65 & $(0.93$ & 2.93 & \\
\hline & & Yes, dissatisfied & 2.11 & $(1.19$ & $3.76)$ & 0.004 \\
\hline & Consulted specialist physician (no) & Once & 2.10 & $(1.15$ & $3.83)$ & \\
\hline & & 2 or more times & 3.08 & $(1.98$ & $4.80)$ & $<.0001$ \\
\hline & Consulted mental health professional* (no) & Yes & 1.48 & $(0.73$ & 3.02) & 0.28 \\
\hline & Visited paramedical staff** (no) & Yes & 1.61 & $(0.98$ & 2.65) & 0.06 \\
\hline & Visited social worker (no) & Yes & 2.54 & $(0.97$ & $6.68)$ & 0.06 \\
\hline
\end{tabular}

Further adjusted for:

living area (rural/urban)

Predisposing factors: marital status (married/single/divorced, separated or widowed), employment status (no/yes),

Evaluated need: bothered by social/personal problems (not at all/a little/a lot), disability (none/mild-moderate/severe), patient declared antidepressant or anxiolytic treatment (past 6 months),

\footnotetext{
* psychiatrist psychologist or psychotherapist

** physiotherapist, osteopath, nurse, etc.
} 